\title{
Can short-term frustration facilitate feather pecking in laying hens?
}

\author{
T.B. Rodenburg* ${ }^{*}$, P. Koene, E.A.M. Bokkers ${ }^{1}$, \\ M.E.H. Bos, K.A. Uitdehaag, B.M. Spruijt
}

Ethology Group, Department of Animal Sciences, Wageningen University, P.O. Box 338, 6700 AH Wageningen, The Netherlands

Received 19 March 2004; received in revised form 16 August 2004; accepted 30 August 2004

Available online 7 October 2004

\begin{abstract}
Feather pecking is a major problem in laying hens. Frustration, i.e. the omission of expected reward, may play a role in the development of feather pecking. In two experiments, we studied if feather pecking could be facilitated by short-term frustration in birds with a high feather pecking phenotype and victims of feather pecking (experiment 1), and in birds with a high or low feather pecking genotype (experiment 2). Furthermore, the motivation to peck a key for a food reward was assessed in birds with a high or low feather pecking genotype in experiment 3 , as birds that have a stronger motivation may also react stronger to the omission of a reward. We trained birds to peck a key for a food reward in an automated Skinnerbox and tested them in control and frustration sessions. During frustration, the feeder was covered with Perspex. Frustration did not facilitate feather pecking in either experiment. In experiment 1, birds with a high feather pecking phenotype did show more gentle feather pecking and aggressive pecking than victims of feather pecking during some of the control sessions. Furthermore, victims of feather pecking vocalised more than birds with a high feather pecking phenotype. In experiment 2 , birds with a high feather pecking genotype scratched more than birds with a low feather pecking genotype, indicating differences in motivation for foraging or dust-bathing behaviour, which shows a relation to feather pecking. Birds with a low feather pecking genotype also had a stronger motivation to peck at a key for a food reward than birds with a high feather pecking genotype. No evidence was found that feather pecking could be facilitated
\end{abstract}

* Corresponding author. Present address: Applied Research Division, Animal Sciences Group, Wageningen UR, P.O. Box 2176, 8203 AD Lelystad, The Netherlands. Tel.: +31 320 293554; fax: +31 320241584.

E-mail address: bas.rodenburg@wur.nl (T.B. Rodenburg).

1 Present Address: Animal Production Systems Group, Department of Animal Sciences, Wageningen University, P.O. Box 338, 6700 AH Wageningen, The Netherlands. 
by short-term frustration in a Skinnerbox. However, differences in reaction to frustration and in motivation to peck a key for a food reward in birds with a high or low feather pecking phenotype or genotype indicate that frustration may still play a role in the development of feather pecking.

(C) 2004 Elsevier B.V. All rights reserved.

Keywords: Feather pecking; Frustration; Operant conditioning; Laying hens

\section{Introduction}

Feather pecking can be characterised as pecking-at and pulling-out of feathers of conspecifics and varies from gentle feather pecking to severe feather pecking (Savory, 1995). Severe feather pecking is considered a major welfare problem. It leads to feather damage and feather loss, high feeding costs due to heat loss, and high mortality rates. Feather pecking is only seen in birds kept in captivity. There are reports on feather pecking in ostriches (Sambraus, 1995), ducks (Raud and Faure, 1994), Japanese quail (Bilcík and Bessei, 1993), pheasants (Hoffmeyer, 1969), and laying hens (Wennrich, 1975). The causation of feather pecking behaviour varies between species. Feather pecking in laying hens is thought to be a form of redirected ground pecking (Blokhuis, 1986) or redirected pecking during dust-bathing (Vestergaard and Lisborg, 1993).

Line differences in feather pecking indicate a genetic background (Hughes and Duncan, 1972). Heritability estimates for feather pecking range from 0.07 to 0.56 (Cuthbertson, 1980; Bessei, 1984; Kjaer and Sørensen, 1997; Rodenburg et al., 2003). Divergent selection on feather pecking has been shown to be feasible (Kjaer et al., 2001). Blokhuis and Beuving (1993) reported differences in feather pecking in two commercial selection lines, selected on production related traits. Therefore these lines were labelled the high (HFP) and low (LFP) feather pecking lines. Line differences in feather pecking have been confirmed both at young age (Riedstra and Groothuis, 2002; Van Hierden et al., 2002a) and at adult age (Rodenburg and Koene, 2003). Furthermore, line differences in corticosterone response to manual restraint have been shown (Korte et al., 1997; Van Hierden et al., 2002b). In a previous study, we found that HFP birds showed a large increase in vocalisations over repeated testing in an individual test, whereas LFP birds showed a decrease (Rodenburg and Koene, 2003).

Frustration, i.e. omission of expected reward, may influence redirection of pecking behaviour. Lindberg and Nicol (1994) proposed a model, in which frustration, for instance because a bird tries to reach the feeder but is unsuccessful, leads to increased arousal, fear and aggression. Under these circumstances, occasional pecks at the plumage may develop into damaging feather pecking. Line differences in feather pecking may be caused by an underlying difference in reaction to frustration. Rodenburg et al. (2002) studied reaction to frustration in HFP and LFP birds and hypothesised that HFP birds would react stronger to frustration than LFP birds, but found the opposite: LFP birds pecked more at the covered feeder and at the keys during frustration than HFP birds. It was argued that HFP birds might have lacked the appropriate substrate to redirect their pecks (feathers or other birds). When feathers were available during frustration in subsequent studies, however, it was found that pecking at feathers in an 
individual context is not comparable with feather pecking in a social context (Rodenburg et al., 2002; Rodenburg and Koene, 2003). Birds were not attracted to peck at a bunch of feathers or feathers fitted around the key of a Skinnerbox. Perhaps feather pecking can be facilitated by frustration if other birds are present.

Reaction to frustration may also be influenced by the motivation a bird has to obtain a certain commodity. If a bird has a stronger motivation to peck a key for a food reward than another bird, it may also show a stronger reaction to frustration, i.e. the omission of that food reward.

The aim of the present experiment was to study if feather pecking can be facilitated by frustration in birds with a high feather pecking phenotype and victims of feather pecking (experiment 1), and in birds with a high or low feather pecking genotype from the HFP and LFP lines (experiment 2). The maximum number of times that birds from the HFP and LFP line would peck for a food reward was assessed in experiment 3. In experiment 1 , birds with an HFP-phenotype were expected to show a stronger reaction to frustration than victims of feather pecking and to show feather pecking during frustration in the presence of a companion bird. In experiment 2, repeated frustration was expected to facilitate the development of feather pecking in HFP birds. In experiment 3, LFP birds were expected to have a stronger motivation to peck a key for a food reward than HFP birds, as they also showed a stronger reaction to frustration in a previous study.

\section{Material and methods}

\subsection{Animals and housing}

\subsubsection{Experiment 1}

For experiment 1, 20 White Leghorn laying hens were selected either as birds with a high feather pecking phenotype (HFP-phenotype) or as victims of feather pecking. These birds were selected from an F2 cross population originating from the HFP- and LFP-lines and obtained from Hendrix Poultry Breeders, Boxmeer, The Netherlands. The original lines were selected for production related traits, but they also showed a difference in feather pecking behaviour (Riedstra and Groothuis, 2002; Van Hierden et al., 2002a; Rodenburg and Koene, 2003). The birds were reared in floor pens on wood shavings in groups of 60 birds. They were kept in this system from 0 through 30 weeks of age. Selection was based on levels of giving and receiving severe and gentle feather pecks in a social feather pecking test at 30 weeks of age. In this feather pecking test, pecking behaviour of a group of five birds was observed for 30 min (Rodenburg and Koene, 2003). Birds that were both feather peckers and victims were excluded from either group. Six additional birds from the same population were used as companion birds. These birds were selected on performing little to no severe feather pecking, to avoid severe feather pecking from the companion bird on the test bird. Feather pecking behaviour of birds with an HFP-phenotype, victims and companion birds is shown in Table 1.

Birds were housed in individual cages of the type described by Van Liere and Wiepkema (1992), measuring $100 \mathrm{~cm} \times 50 \mathrm{~cm} \times 50 \mathrm{~cm}(l \times w \times h)$. Each cage was equipped with a dust-bath filled with sand and a nestbox and had a partly slatted floor. Food and water were 
Table 1

Mean number of bouts of gentle and severe feather pecking as pecker $\left(P_{\text {gent }} / P_{\text {seve }}\right)$ and as victim $\left(V_{\text {gent }} / V_{\text {seve }}\right)$ per $30 \mathrm{~min}$ in birds with a HFP-phenotype, victims, and companion birds selected for experiment 1

\begin{tabular}{llllll}
\hline Group & $N$ & $P_{\text {gent }}$ & $P_{\text {seve }}$ & $V_{\text {gent }}$ & $V_{\text {seve }}$ \\
\hline HFP-phenotype & 10 & 2.3 & 4.3 & 0 & 0 \\
Victims & 10 & 0.1 & 0 & 2.8 & 2.8 \\
Companion & 6 & 1.9 & 0.6 & 2.4 & 3.3 \\
\hline
\end{tabular}

available ad libitum. Lights were on from 3:00 h until 19:00 h. The Wageningen University Committee on Animal Care and Use has approved experiments 1 and 2.

\subsubsection{Experiment 2}

Thirty beak-trimmed White Leghorn laying hens of 18 weeks old were obtained from Hendrix Poultry Breeders, Boxmeer, The Netherlands. These hens originated from the high and low feather pecking lines. After arrival at the research accommodation, each bird was marked individually with a wing tag and housed individually in the same cages as described in experiment 1 . The birds had no feather damage when they arrived, hence we assumed they had no prior experience with (severe) feather pecking and considered them to be naive birds concerning feather pecking. Birds were fed restrictedly at $75 \%$ of their food intake when fed ad libitum throughout the week. This was done by measuring each bird's food intake at 19 weeks of age. From 25 weeks of age, food rations were increased to allow for the birds increased requirements during egg laying. Lights were on from 3:00 h until 18:00 h.

\subsection{Apparatus}

Three automated Skinnerboxes were used of the type described by Zimmerman and Koene (1998). They were located in a sound attenuated room, close to the home cages. Each Skinnerbox measured $60 \mathrm{~cm} \times 50 \mathrm{~cm} \times 65 \mathrm{~cm}$. Three lighted keys were present $10 \mathrm{~cm}$ apart on the intelligence panel, $26 \mathrm{~cm}$ above the floor. The feeder was accessible through a round hole $(12 \mathrm{~cm}$ in diameter) in the centre of the intelligence panel, $10 \mathrm{~cm}$ above the floor. Food was only accessible when the feeder was raised. The presence or absence of a bird's head in the feeder was detected by a photocell. A 5-W house-light was fixed $8 \mathrm{~cm}$ above each Skinnerbox. The Skinnerboxes were operated through a custommade program, using LabView ${ }^{\circledR}$ software (National Instruments, 1994). Changes in key lights (on or off), keys (peck or no peck) and photocells (head or no head) were automatically recorded and stored on disk. Skinnerboxes and computer were located in the same room.

\subsection{Training procedure experiment 1}

The birds were about 35 weeks old when the experiment started. The experiment lasted for 4 weeks. Each bird was habituated to a Skinnerbox for $15 \mathrm{~min}$ on the first day of shaping. On the following days, each bird was food deprived for $23 \mathrm{~h}$ per day throughout 
the experiment. This was done by depriving the birds from food for $23 \mathrm{~h}$ on Monday and testing the birds on Tuesday through Friday. After each 15-min session, birds could eat for 45 min. After the sessions on Friday, birds could eat ad libitum through Sunday. Food deprivation was needed to motivate the birds to work for a food reward in the Skinnerbox. Auto-shaping was used to train the birds to press one of the three keys for a food reward. During auto-shaping all keys were illuminated every $30 \pm 2 \mathrm{~s}$. The keys were illuminated for $10 \mathrm{~s}$ and after that, the feeder was raised and the bird was allowed to eat for $5 \mathrm{~s}$ (classical conditioning). This auto-shaping procedure can be used to train birds to peck a key through pairings of illumination of that key with food (Lieberman, 1993, pp. 96-97). When all birds were pecking at the keys during auto-shaping, each bird was trained to peck a key when the stimulus lights were on, using operant training. They were trained for $15 \mathrm{~min}$ per day. The house-light was on from the start to the end of each session. The training sessions were identical to the auto-shaping sessions, only during training birds had to press one of the keys to obtain a food reward. Each bird was trained until the training criterion was reached: at least $95 \%$ correct key pecks and head in the feeder within $2 \mathrm{~s}$ after the feeder was raised. Two birds from the group of victims did not reach the training criterion. Hence, 10 birds with an HFP-phenotype and eight victims were subjected to the test procedure.

\subsection{Test procedure experiment 1}

Birds were tested between 10:00 $\mathrm{h}$ and 16:00 $\mathrm{h}$ to avoid interference with egg laying. After each session, food was available for $45 \mathrm{~min}$. After that, birds were food deprived for another $23 \mathrm{~h}$. Birds were subjected to three 15-min test sessions on three consecutive days of approximately 30 trials each: a pre-control session, a frustration session and a post-control session. Food was normally accessible during both control sessions. During the frustration session the feeder was covered with Perspex ${ }^{\circledR}$, allowing the birds to see the food, but not to reach it. These three sessions were repeated in the two subsequent weeks in the presence of a companion bird. On the first day of each of these 2 weeks, birds were habituated to one specific companion bird. On days 2-4 the control and frustration sessions as described before were repeated in the presence of this companion bird. In the second week, the same procedure was followed, but with a different companion bird. Behaviour was recorded on videotape and analysed with The Observer ${ }^{\circledR}$ programme (Noldus, 1993) using focal sampling. The ethogram is described in Table 2. Pacing and making escape movements were mutually exclusive (states). The pecks, vocalisations and scratches were recorded as events and could also occur during pacing or during making escape movements.

\subsection{Habituation and training experiment 2}

For experiment 2, the same three automated Skinnerboxes were used as in experiment 1. Each bird was habituated to a Skinnerbox for $15 \mathrm{~min}$ on the first and the second day of shaping. The extra day of habituation compared with experiment 1 was added because the experimenters had indications from experiment 1 that this might result in a shorter training period. After 2 days of habituation, birds were fed restrictedly and trained to peck at a key in the Skinnerbox using auto-shaping (see experiment 1 for auto-shaping procedure). After each bird had been subjected to 14 auto-shaping sessions, six sessions of operant training 
Table 2

Ethogram experiments 1 and 2

\begin{tabular}{ll}
\hline Behaviour & Description \\
\hline Key peck & Peck at one of the keys \\
Covered feeder peck & a \\
Redirected peck & Peck at the covered feeder \\
Scratch & Peck at other parts of Skinnerbox \\
Escape movement & Backward stroke with one leg \\
Pacing & Pacing in front of the exit \\
Alarm call & Pacing in front of the keys \\
Gakel call & [Kot kot kot kodeek] \\
Aggressive peck & [Pwook pwok pwok pwok] \\
Gentle feather peck & Aggressive peck at head or neck of companion bird \\
Severe feather peck & Small neck movement, no reaction victim \\
\hline
\end{tabular}

${ }^{\text {a }}$ Only possible during the frustration session.

followed (see experiment 1). During these sessions, a bird had to peck a key when the stimulus lights were on. After these sessions, birds that were unable to perform the task were trained using hand shaping, followed again by operant training for all birds. After operant training and hand shaping, birds were habituated to the presence of a companion bird during two consecutive days. These habituation sessions were also used to select the companion birds that would be used in the test sessions. A companion bird was selected when it did not show any aggressive behaviour. At the last 2 days of training and habituation, each bird was required to reach the training criterion: at least $95 \%$ correct key pecks and head in the feeder within $2 \mathrm{~s}$ after the feeder was raised on both days.

\subsection{Test procedure experiment 2}

During the test sessions, birds were still fed restrictedly at $75 \%$ and subjected to five $15-$ min test sessions of approximately 30 trials each: a control session on Monday and four frustration sessions on the four subsequent weekdays. A factorial arrangement was used with line (HFP or LFP) and companion bird (present or not present) as factors. Five birds per line were tested with a companion bird in week 1 and without a companion bird in week 2 and five birds per line were subjected to the reverse order of testing. The order in which the birds were tested was kept the same during the experiment. Food was normally accessible during the control session. During the frustration sessions the feeder was covered with Perspex ${ }^{\circledR}$, allowing the birds to see the food, but not to reach it. Birds were tested between 10:00 $\mathrm{h}$ and 16:00 $\mathrm{h}$ to avoid interference with egg laying. After each session, birds received their daily food ration. Behaviour was recorded on videotape and analysed with The Observer ${ }^{\circledR}$ programme (Noldus, 1993) using focal sampling. The ethogram was the same as used in experiment 1 (Table 2).

\subsection{Experiment 3}

Three days after the repeated frustration experiment, the maximum number of key pecks a bird would give to obtain a food reward was measured in the same 21 birds. Birds were 
still fed restrictedly at $75 \%$ of ad libitum. They were re-trained to peck at the left key only, because the computer programme used could operate only the left key. After this training day, birds were subjected in random order to $a+2$ progressive ratio or +4 progressive ratio, e.g. the number of pecks required to obtain a food reward incremented with two or with four pecks after each rewarded trial. Maximum session time was $30 \mathrm{~min}$, but a session was also ended when a bird failed to obtain a reward and also failed in the subsequent trial. After the two test days, birds were fed unrestrictedly for 4 days. Then, birds were tested again under unrestricted feed conditions using $\mathrm{a}+2$ progressive ratio.

\subsection{Statistical analysis}

For experiment 1, analysis of variance was performed using the GLM-procedure in the SAS $^{\circledR}$ statistical programme (SAS, 1996). Frequencies and durations of all observed behaviours were transformed with a square root transformation or an arcsine square root transformation, respectively, to realise normal distributions. Group (feather pecker or victim) was the only fixed effect included in the model. Since birds with an HFP-phenotype and victims of feather pecking were tested alternately, testing order was not included. To compare the frustration session to both control sessions, sessions were analysed as repeated measures.

For experiment 2, a similar analysis was performed. Line, testing order (first with companion and then without companion and vice versa), and time of testing were included in the model as fixed effects. The effect of frustration was calculated by comparing the first frustration session to the control session. The effect of repeated frustration was calculated by analysing the four subsequent frustration sessions as repeated measures.

To measure each bird's motivation to peck a key for food in experiment 3 , the maximum number of pecks that each bird delivered in each of the three test sessions was calculated. Data were analysed with line and time of testing as fixed effects.

\section{Results}

\subsection{Experiment 1}

No differences were found in number of key pecks between birds with an HFPphenotype and victims of feather pecking, nor between control and frustration sessions (Fig. 1). Birds showed more redirected pecking during the frustration sessions compared with both control sessions $\left(F_{1,16}=15.62, P<0.01\right)$. No difference was found in covered feeder pecking during the frustration session between birds with an HFP-phenotype (mean $15.6 \pm 2.4$ ) and victims (mean $17.9 \pm 3.4$ ).

The mean number of gakel calls and alarm calls in birds with an HFP-phenotype and victims of feather pecking in the control and frustration sessions without a companion bird are shown in Fig. 2. The total number of vocalisations recorded was low in all three sessions. During the frustration session, victims of feather pecking produced more gakel calls than birds with a HFP-phenotype $\left(F_{1,16}=4.73, P<0.05\right)$. Victims also produced 


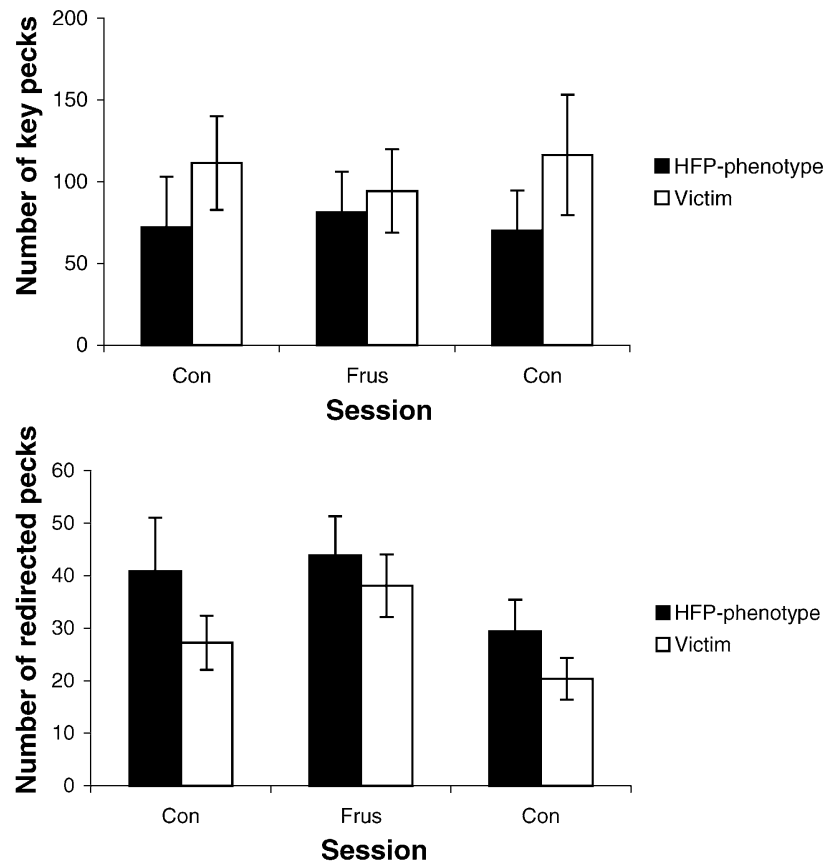

Fig. 1. Mean number of key pecks (top panel) and redirected pecks (bottom panel) in birds with an HFPphenotype and victims of feather pecking in the control (con) and frustration (frus) sessions without a companion bird.

more alarm calls than birds with a HFP-phenotype during the second control session $\left(F_{1,16}\right.$ $=5.26, P<0.05)$.

Levels of gentle feather pecking were low in week 1 and no increase was found as an effect of frustration (Fig. 3). In week 2, there was a tendency for an increase in gentle feather pecking over time $\left(F_{1,16}=3.66, P<0.10\right)$. In the first control session in week 2 , birds with a HFP-phenotype showed more-gentle feather pecking than victims $\left(F_{1,16}=\right.$ $4.88 ; P<0.05)$. For severe feather pecking, there was a large increase for the birds with an HFP-phenotype in the frustration session in week 1, but the difference was not significant, as it was only one bird performing 141 severe pecks in this session. The same bird showed a high level of severe feather pecking (130 pecks) during the habituation session in week 2 . Levels of severe feather pecking were higher in week 2 than in week 1. Birds with a HFPphenotype tended to show more aggressive pecking than victims during the second control session in week $1\left(F_{1,16}=3.32, P<0.10\right)$. Furthermore, victims showed an increase in aggression as a result of frustration, whereas the level of aggression in birds with a HFPphenotype stayed the same compared with the control session $\left(F_{1,16}=7.01, P<0.05\right)$.

\subsection{Experiment 2}

Key pecking showed a linear decrease over the repeated frustration sessions $\left(F_{1,11}=\right.$ 24.25, $P<0.001$, Fig. 4). Redirected pecking showed a linear increase from the first 

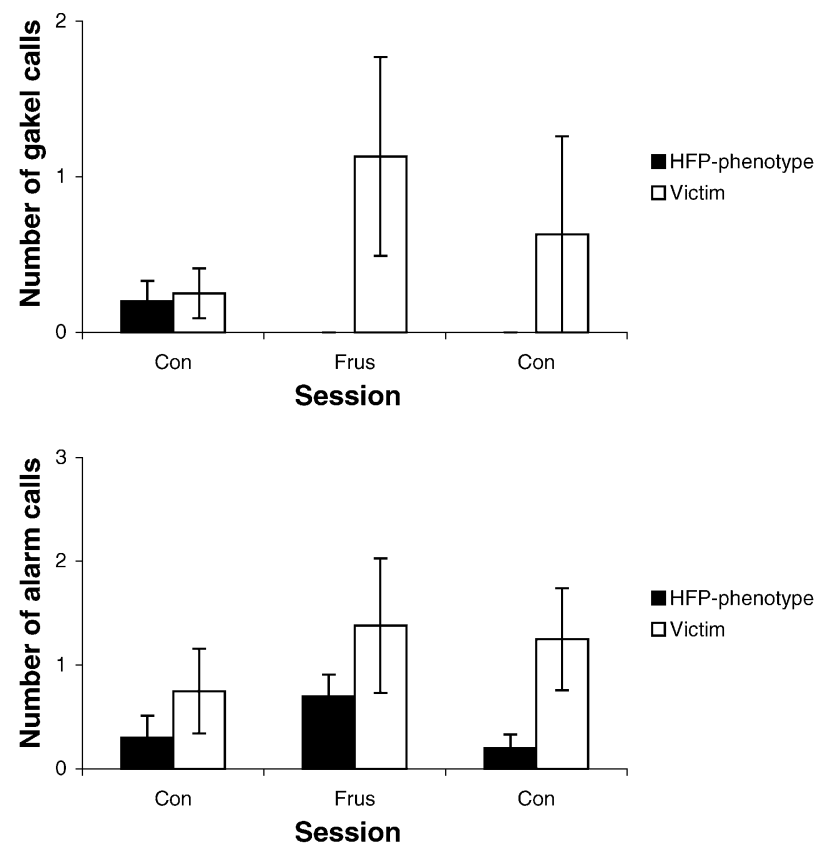

Fig. 2. Mean number of gakel calls (top panel) and alarm calls (bottom panel) in birds with an HFP-phenotype and victims of feather pecking in the control (con) and frustration (frus) sessions without a companion bird.

through the fourth frustration session $\left(F_{1,11}=11.03, P<0.01\right)$. Levels of covered feeder pecking were highest during the first frustration session. Over the repeated frustration sessions, a linear decrease was found for covered feeder pecking $\left(F_{1,11}=25.38, P<0.001\right)$. There was no difference in covered feeder pecking between HFP birds and LFP birds $\left(F_{1,12}\right.$ $=1.24, P=0.29$ ). No line differences were found in reaction to frustration in the sessions without a companion bird.

HFP birds scratched more than LFP birds over all sessions $\left(F_{1,12}=11.67, P<0.01\right.$, Fig. 5). A decrease of scratching behaviour was found from the control session to the first frustration session $\left(F_{1,12}=20.18, P<0.001\right)$ and over the repeated frustration sessions an overall line difference was found $\left(F_{1,12}=11.67, P<0.01\right)$. No line differences were found for time spent pacing or time spent making escape movements. Time spent pacing in front of the keys showed a linear decrease over repeated frustration $\left(F_{1,12}=5.66, P<0.05\right)$, whereas time spent making escape movements in front of the entrance of the Skinnerbox increased as an effect of frustration. This increase, however, was not significant, neither was the difference in aggressive pecking between HFP and LFP birds.

The mean number of gentle feather pecks and aggressive pecks in HFP and LFP birds during control and repeated frustration sessions with a companion bird are shown in Fig. 6 . Levels of feather pecking were low in this experiment. In fact, severe feather pecking was not observed at all. Gentle feather pecking was only observed during the frustration sessions, but levels were low and no differences were found between HFP and LFP birds. Aggressive pecking was observed both during control and frustration sessions. There was a 

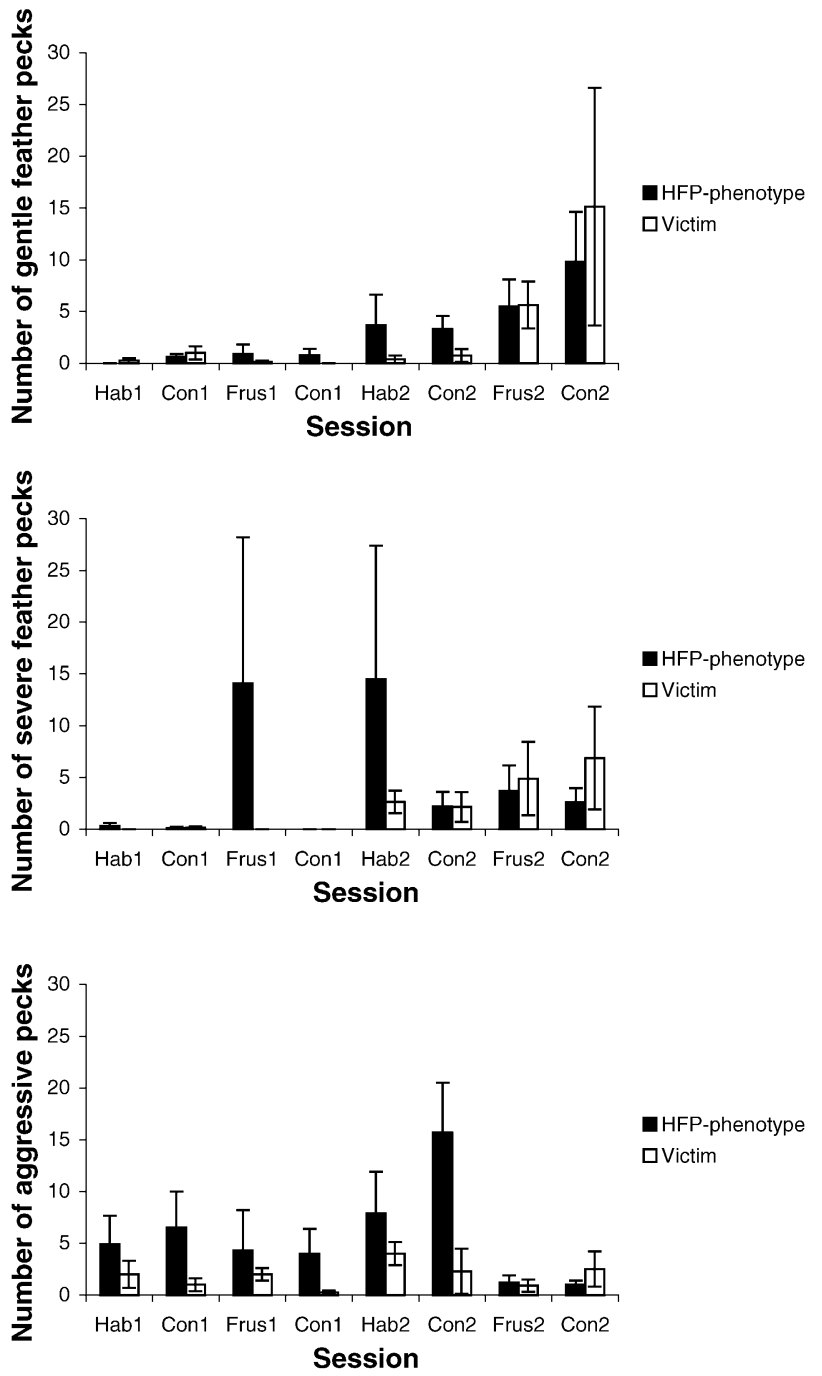

Fig. 3. Mean number of gentle feather pecks (top panel), severe feather pecks (middle panel) and aggressive pecks (bottom panel) in birds with an HFP-phenotype and victims of feather pecking in habituation (hab), control (con) and frustration (frus) sessions in week 1 (hab1, etc.) and week 2 (hab 2, etc.) with a companion bird.

slight but non-significant increase in the first frustration session and a slight decrease over repeated frustration $\left(F_{1,12}=2.31, P=0.15\right)$.

\subsection{Experiment 3}

The maximum number of key pecks given to obtain a food reward in HFP and LFP lines under +2 restricted, +4 restricted and +2 unrestricted progressive ratios is shown in Fig. 7 . LFP tended to give a higher maximum number of key pecks for a food reward than HFP 

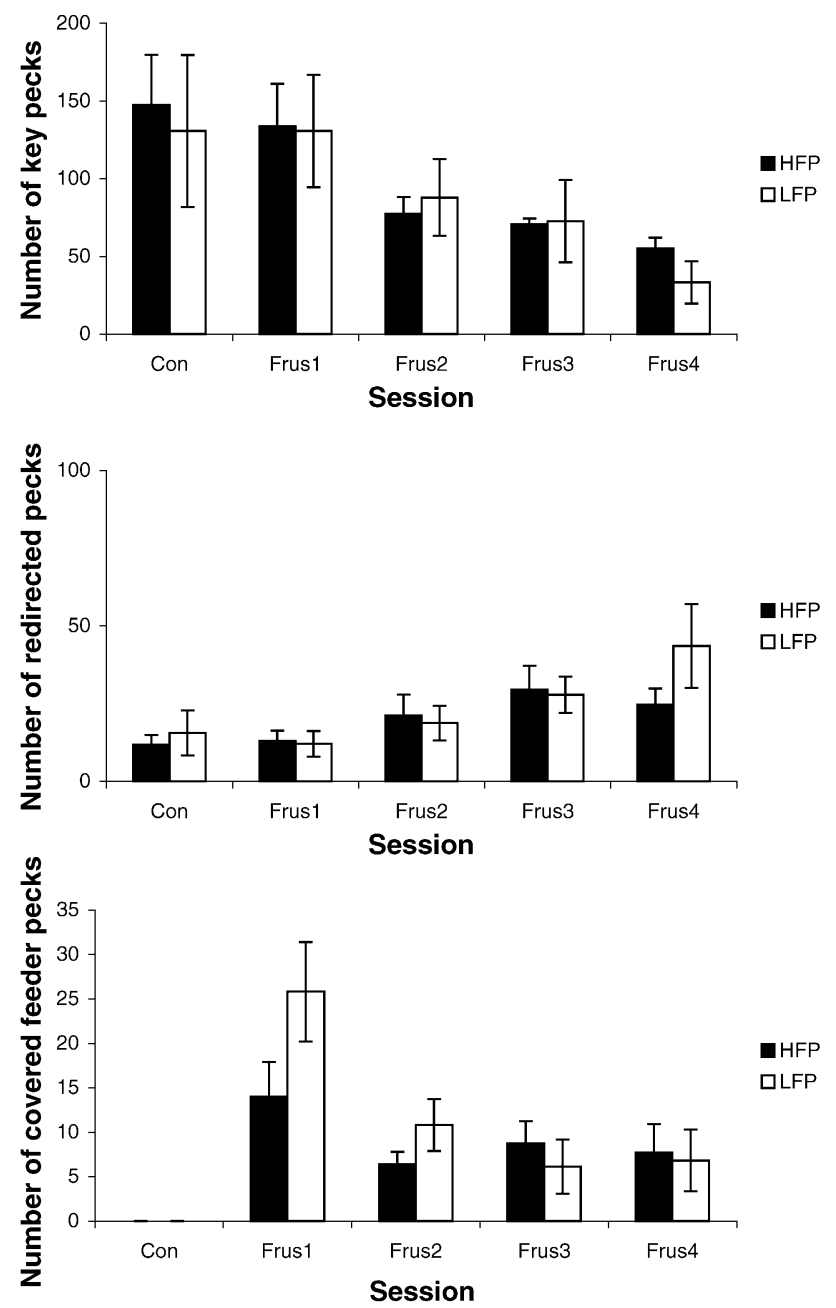

Fig. 4. Mean number of key pecks (top panel), redirected pecks (middle panel) and covered feeder pecks (bottom panel) in HFP and LFP birds during control (con) and repeated frustration sessions (frus 1-4) without a companion bird.

birds under +2 restricted $\left(F_{1,19}=3.78, P<0.10\right)$, and under +2 unrestricted $\left(F_{1,19}=3.93\right.$, $P<0.10)$ conditions.

\section{Discussion}

Gentle and severe feather pecking could not be facilitated by short-term frustration in experiments 1 and 2. In the study by Lindberg and Nicol (1994), feather pecking did develop over time and groups with operant feeders showed more feather pecking than 

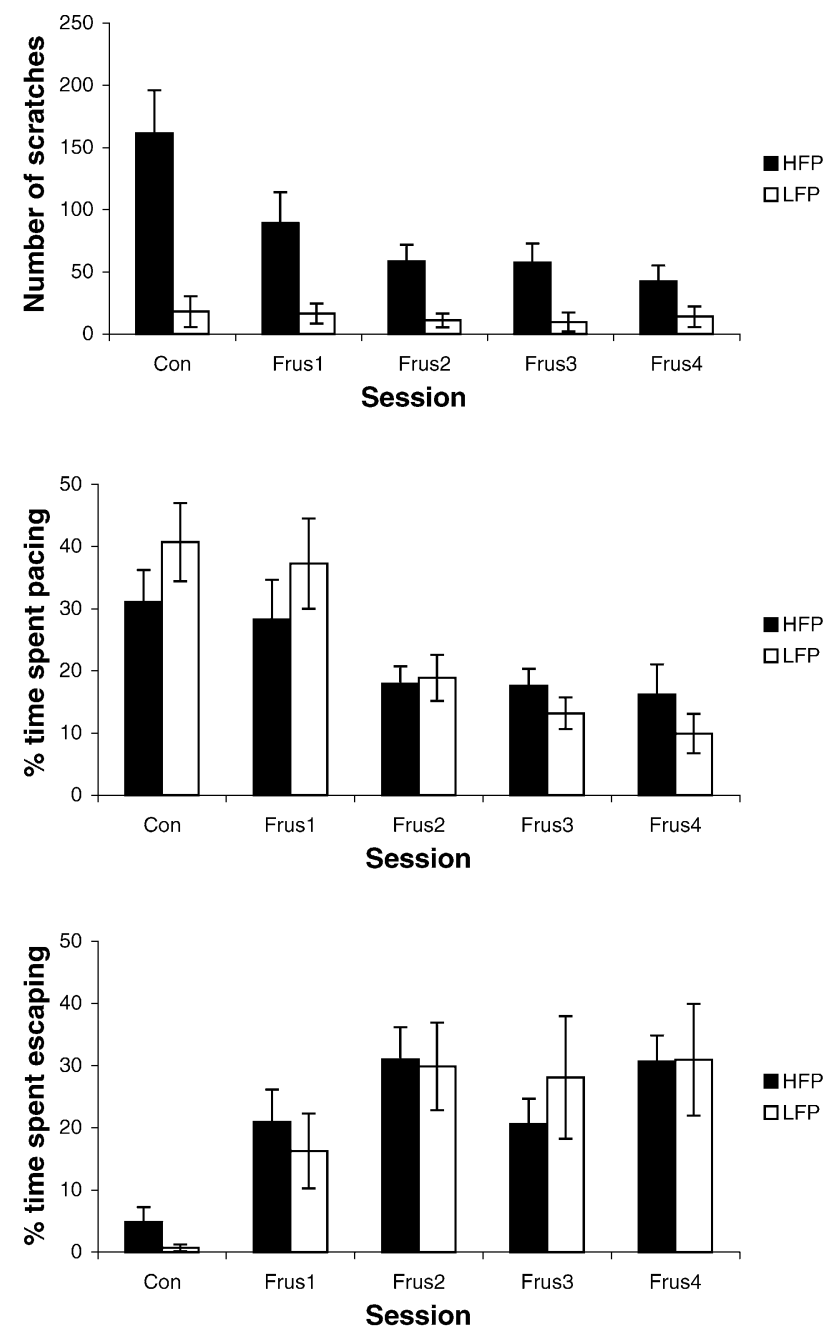

Fig. 5. Mean number of scratches (top panel) and the time spent pacing (middle panel) and the time spent making escape movements (bottom panel) in HFP and LFP birds during control (con) and repeated frustration sessions (frus 1-4) without a companion bird.

groups with normal feeders. In another study, where a dominant test-bird was frustrated in a runway in the presence of a sub-dominant companion bird, both aggression and feather pecking were observed as an effect of frustration (Haskell et al., 2000).

The fact that we did not find similar results might be explained by the fact that we still used short-term frustration sessions in this study, although we used repeated sessions in experiment 2. Furthermore, this study may show that the Skinnerbox is less suited for the study of bird-to-bird pecking. The reason why the Skinnerbox was chosen for this experiment was that it is a very controllable environment, where birds can be tested at 


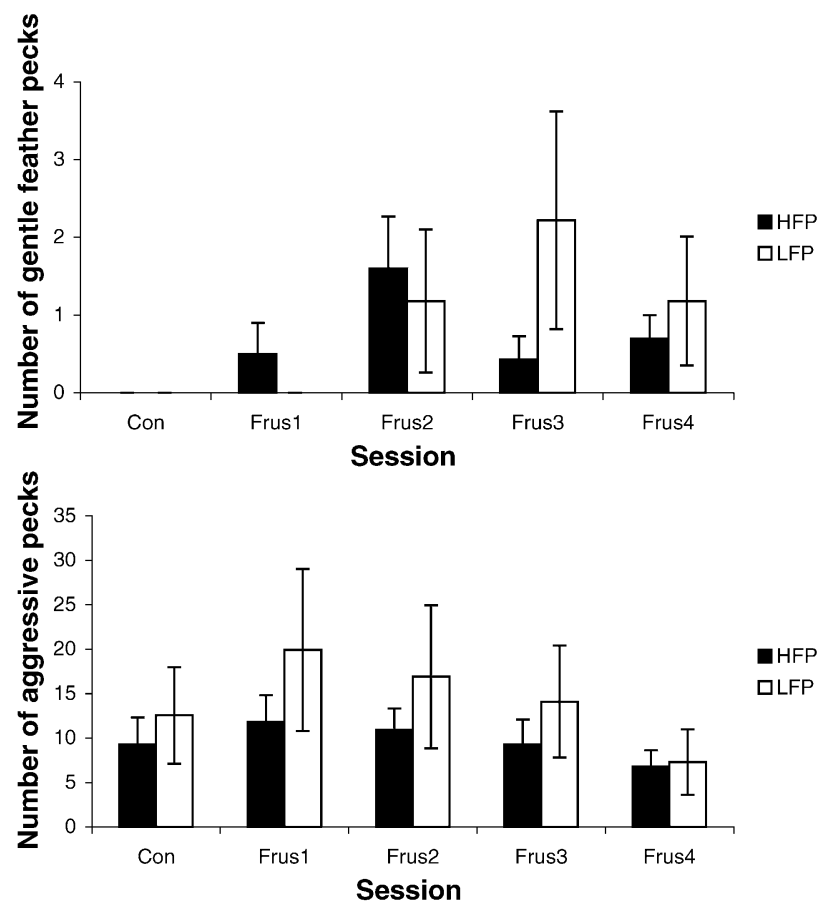

Fig. 6. Mean number of gentle feather pecks (top panel) and aggressive pecks (bottom panel) in HFP and LFP birds during control (con) and repeated frustration sessions (frus 1-4) with a companion bird.

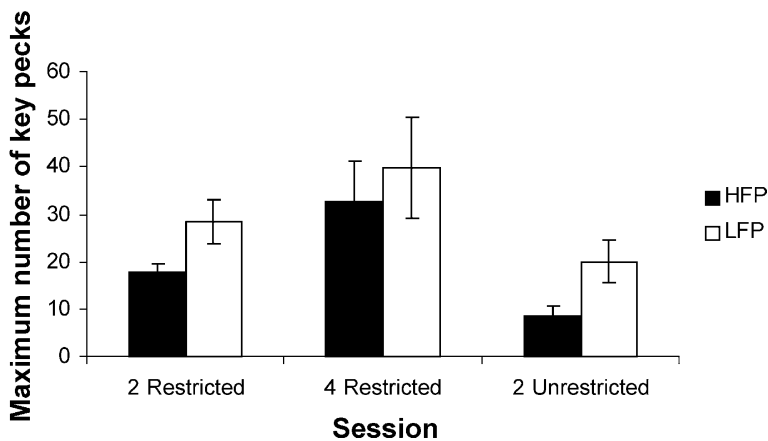

Fig. 7. Maximum number of key pecks given for a food reward in HFP and LFP lines under +2 restricted, +4 restricted and +2 unrestricted progressive ratios.

individual level. Development of feather pecking in a group of birds in their home environment may be very difficult to imitate in the Skinnerbox environment.

In experiment 1 , birds with an HFP-phenotype did show more-gentle feather pecking and more aggressive pecking than victims during some control sessions, but no significant differences in severe feather pecking was found. Victims showed an increase in aggression 
in reaction to frustration in week 1, whereas birds with an HFP-phenotype showed a higher level of aggression throughout the whole experiment. Aggressive pecking and feather pecking are distinct forms of pecking (Savory, 1995). It may be, however, that birds with an HFP-phenotype are also the most aggressive birds. Frustration induced aggression has been described in pigs (Arnone and Dantzer, 1980), as well as in laying hens (Duncan and WoodGush, 1971; Haskell et al., 2000). In experiment 1, it seems that only victims showed frustration induced aggression, whereas birds with an HFP-phenotype showed aggression irrespective of the session. In experiment 2 , the difference between control and frustration was not significant.

In the sessions without a companion bird in experiment 1 , birds showed more redirected pecking during the frustration sessions compared with both control sessions. No difference was found in covered feeder pecking during the frustration session between birds with an HFP-phenotype and victims. In experiment 2, key pecking and covered feeder pecking showed a decrease over the repeated frustration sessions, whereas redirected pecking showed an increase. No line differences were found in reaction to frustration in the sessions without a companion bird. Although LFP birds showed more covered feeder pecking than HFP birds during the first frustration as was found in a previous study (Rodenburg et al., 2002), this difference was not significant. In both experiments, redirected pecking increased as an effect of frustration, as was also found by Duncan and Wood-Gush (1972).

In experiment 1, differences were found in vocalisations. During the frustration session, victims of feather pecking produced more gakel calls than birds with an HFP-phenotype. Victims also produced more alarm calls than birds with an HFP-phenotype during the second control session. Zimmerman and Koene (1998) showed that the number of gakel calls increased as an effect of frustration, whereas alarm-calls were recorded both during control and frustration sessions and seem to indicate anxiety. The results from the present study indicate that victims of feather pecking are more affected by omission of expected reward than birds with a HFP-phenotype and that they show higher levels of anxiety, as indicated by the number of alarm calls in the second control session.

In experiment 2, HFP birds scratched more than LFP birds over all sessions. A decrease of scratching behaviour was found from the control session to the first frustration session and over the repeated frustration sessions an overall line difference was found. Contrary to the line difference we found, Klein et al. (2000) showed that a strain that showed higher levels of feather pecking than other strains spent less time scratching. Feather pecking is thought to be a form of redirected ground pecking (Blokhuis, 1986) or redirected pecking during dust-bathing (Vestergaard and Lisborg, 1993). There is more evidence for the theory that feather pecking develops from ground pecking, however, as Huber-Eicher and Wechsler (1997) showed that provision of sand did not prevent feather pecking, whereas the provision of straw led to a reduction of feather pecking. As scratching is part of both foraging and dust-bathing behaviour, it could be that HFP birds are more motivated for these behaviours and hence more likely to develop feather pecking. Results from other studies, however, showed that LFP birds performed more foraging behaviour in homepen observations than HFP birds (Van Hierden et al., 2002a; Rodenburg and Koene, 2003). In the homepen, litter is available and pecking and scratching in the litter is functional and can produce reward, i.e. food items in the litter. In the Skinnerbox, key pecking is rewarded, but not pecking and scratching on the floor of the Skinnerbox. The difference may be explained 
by a difference in the way these lines cope with their environment. LFP birds may be more environment-directed (reactive coper) and HFP birds may be less flexible and reactive to the environment (pro-active coper), as was suggested by Rodenburg and Koene (2003).

Pacing and making escape movements were the only behaviours in experiment 2 where a clear effect of repeated frustration was found. Time spent pacing in front of the keys showed a linear decrease over repeated frustration, whereas time spent making escape movements in front of the entrance of the Skinnerbox increased as an effect of frustration. It seems that over the repeated frustration sessions, birds tended to loose their interest in the control panel of the Skinnerbox, as this was no longer rewarding, and were more interested in escaping the Skinnerbox environment to return to the homecage, as may be expected.

In experiment 3 we found that LFP tended to give a higher maximum number of pecks for a food reward than HFP birds, both under +2 restricted, and under +2 unrestricted progressive ratios, as hypothesised. Korte et al. (1997) suggested that HFP birds en LFP birds may have different coping strategies. HFP birds may be characterised as proactive copers and LFP birds as reactive copers. Rodenburg et al. (2002) hypothesised that HFP birds, being proactive copers, would react stronger to frustration than LFP birds, but found the opposite: LFP birds pecked more at the covered feeder and at the keys during frustration than HFP birds. It was argued that HFP birds might have lacked the appropriate substrate to redirect their pecks at (other birds), but the current study showed that in the presence of other birds HFP birds did not show more feather pecking than LFP birds. The current finding that LFP birds worked harder to obtain a food reward than HFP birds fits well with the previous findings that LFP birds pecked more at the keys and the covered feeder during frustration (Rodenburg et al., 2002).

In conclusion, no evidence was found that feather pecking could be facilitated by shortterm frustration in a Skinnerbox, neither in birds with an HFP-phenotype and victims of feather pecking, nor in naive HFP and LFP birds using repeated frustration. However, differences in reaction to frustration between birds with a HFP-phenotype or genotype and non-feather peckers in both experiments indicate that frustration may still play a role in the development of feather pecking. In future research, paradigms using long-term frustration in the homepen should be used to study the relationship between feather pecking and frustration further. This could be done by training groups of feather peckers and groups of non-feather peckers to feed from an operant feeder in the homepen and then study the effect of frustration in the homepen on the development of feather pecking and aggressive pecking.

\section{Acknowledgements}

The authors would like to thank Hendrix Poultry Breeders for kindly providing the birds and the animal caretakers of experimental farm 'De Haar' for taking good care of the laying hens. Furthermore, we thank Patrick Zimmerman for designing the computer program used to operate the automated Skinnerboxes. This project was funded by the Netherlands Organisation for Scientific Research (NWO; grant ALW, PPWZ 80546.052). 


\section{References}

Arnone, M., Dantzer, R., 1980. Effects of diazepam on extinction induced aggression in pigs. Pharmacol. Biochem. Behav. 13, 27-30.

Bessei, W., 1984. Untersuchungen zur Heritabilität des Federpickverhaltens bei Junghennen. I. Mitteilung. Arch. Geflügelk. 48, 224-231.

Bilcík, B., Bessei, W., 1993. Feather pecking in Japanese quail: comparison of six different lines.. In: Nichelmann, M., Wieringa, H.K., Braun, S. (Eds.), Proceedings of the International Congress on Applied Ethology. Berlin, Germany, pp. 291-293.

Blokhuis, H.J., 1986. Feather-pecking in poultry: its relation with ground-pecking. Appl. Anim. Behav. Sci. 16, 63-67.

Blokhuis, H.J., Beuving, G., 1993. Feather pecking and other characteristics in two lines of laying hen. In: Proceedings of the fourth European Symposium on Poultry Welfare. Edinburgh, United Kingdom, pp. 266267.

Cuthbertson, G.J., 1980. Genetic variation in feather-pecking behaviour. Br. Poult. Sci. 21, 447-450.

Duncan, I.J.H., Wood-Gush, D.G.M., 1971. Frustration and aggression in the domestic fowl. Anim. Behav. 19, 500-504.

Duncan, I.J.H., Wood-Gush, D.G.M., 1972. Thwarting of feeding behaviour in the domestic fowl. Anim. Behav. 20, 444-451.

Haskell, M., Coerse, N.C.A., Forkman, B., 2000. Frustration-induced aggression in the domestic hen: the effect of thwarting access to food and water on aggressive responses and subsequent approach tendencies. Behaviour $137,531-546$.

Hoffmeyer, I., 1969. Feather pecking in pheasants: an ethological approach to the problem. Danish Rev. Game Biol. 6, 1-36.

Hughes, B.O., Duncan, I.J.H., 1972. The influence of strain and environmental factors upon feather pecking and cannibalism in fowls. Br. Poult. Sci. 13, 525-547.

Kjaer, J.B., Sørensen, P., 1997. Feather pecking behaviour in White Leghorns, a genetic study. Br. Poult. Sci. 38, 333-341.

Kjaer, J.B., Sørensen, P., Su, G., 2001. Divergent selection on feather pecking behaviour in laying hens (Gallus gallus domesticus). Appl. Anim. Behav. Sci. 71, 229-239.

Klein, T., Zeltner, E., Huber Eicher, B., 2000. Are genetic differences in foraging behaviour of laying hen chicks paralleled by hybrid-specific differences in feather pecking? Appl. Anim. Behav. Sci. 70, 143-155.

Korte, S.M., Beuving, G., Ruesink, W., Blokhuis, H.J., 1997. Plasma catecholamine and corticosterone levels during manual restraint in chicks from a high and low feather pecking line of laying hens. Physiol. Behav. 62, 437-441.

Lieberman, D.A., 1993. Learning, behavior and cognition. Brooks/Cole Publishing Company, Pacific Grove, California, USA.

Lindberg, A.C., Nicol, C.J., 1994. An evaluation of the effect of operant feeders on welfare of hens maintained on litter. Appl. Anim. Behav. Sci. 41, 211-227.

National Instruments, 1994. Labview Function Reference Manual, version 3.1, National Instruments, Woerden, The Netherlands.

Noldus, 1993. The Observer $\AA$ : Base package for Dos. Reference Manual, version 3.0, Noldus Information Technology, Wageningen, The Netherlands.

Raud, H., Faure, J.M., 1994. Welfare of ducks in intensive units. Rev. Sci. Tech. 13, 119-129.

Riedstra, B., Groothuis, T.G.G., 2002. Early feather pecking as a form of social exploration: the effect of group stability on feather pecking and tonic immobility in domestic chicks. Appl. Anim. Behav. Sci. 77, 127-138.

Rodenburg, T.B., Zimmerman, P.H., Koene, P., 2002. Reaction to frustration in high and low feather pecking laying hens. Behav. Process. 59, 121-129.

Rodenburg, T.B., Buitenhuis, A.J., Ask, B., Uitdehaag, K.A., Koene, P., Van der Poel, J.J., Bovenhuis, H., 2003. Heritability of feather pecking and open-field response in laying hens at two different ages. Poult. Sci. 82, 861867.

Rodenburg, T.B., Koene, P., 2003. Comparison of individual and social feather pecking tests in two lines of laying hens at ten different ages. Appl. Anim. Behav. Sci. 81, 133-148. 
Sambraus, H.H., 1995. Behavior disorders in relation to food intake in African ostriches. Berl. Munch. Tierarztl. Wochenschr. 108, 344-346.

SAS, 1996. SAS ${ }^{\circledR}$ proprietary software release 6.12 , Copyright $1989-1996$ by SAS Institute Inc. SAS Institute, Cary, NC, USA.

Savory, C.J., 1995. Feather pecking and cannibalism. Worlds Poult. Sci. J. 51, 215-219.

Van Hierden, Y.M., Korte, S.M., Ruesink, E.W., Van Reenen, C.G., Engel, B., Koolhaas, J.M., Blokhuis, H.J., 2002a. The development of feather pecking behaviour and targeting of pecking in chicks from a high and low feather pecking line of laying hens. Appl. Anim. Behav. Sci. 77, 183-196.

Van Hierden, Y.M., Korte, S.M., Ruesink, E.W., Van Reenen, C.G., Engel, B., Korte-Bouws, G.A.H., Koolhaas, J.M., Blokhuis, H.J., 2002b. Adrenocortical reactivity and central serotonin and dopamine turnover in young chicks from a high and low feather-pecking line of laying hens. Physiol. Behav. 75, 653-659.

Van Liere, D.W., Wiepkema, P.R., 1992. Effects of long-term deprivation of sand on dust-bathing behaviour in laying hens. Anim. Behav. 43, 549-558.

Vestergaard, K.S., Lisborg, L., 1993. A model of feather pecking development which relates to dust-bathing in the fowl. Behaviour 126, 291-308.

Wennrich, G., 1975. Ethological studies of domestic chickens (Gallus domesticus) of different hybrid origin in floor management with special reference to aggressive behaviour as well as feather pecking and cannibalism 5 . Communication: feather pecking behaviour. Arch. Geflügelk. 39, 37-44.

Zimmerman, P.H., Koene, P., 1998. The effect of frustrative nonreward on vocalisations and behaviour in the laying hen, Gallus gallus domesticus. Behav. Process. 44, 73-79. 